\title{
Subchronic Continuous Phencyclidine Administration Potentiates Amphetamine-Induced Frontal Cortex Dopamine Release
}

\author{
Andrea Balla', Henry Sershen ${ }^{1,2}$, Michael Serra', Rajeth Koneru' and Daniel C Javitt*,1,2 \\ 'Nathan Kline Institute for Psychiatric Research, Orangeburg, NY, USA; '2Department of Psychiatry, New York University School of Medicine, \\ New York, NY, USA
}

Functional dopaminergic hyperactivity is a key feature of schizophrenia. Etiology of this dopaminergic hyperactivity, however, is unknown. We have recently demonstrated that subchronic phencyclidine (PCP) treatment in rodents induces striatal dopaminergic hyperactivity similar to that observed in schizophrenia. The present study investigates the ability of PCP to potentiate amphetamine-induced dopamine release in prefrontal cortex (PFC) and nucleus accumbens (NAc) shell. Prefrontal dopaminergic hyperactivity is postulated to underlie cognitive dysfunction in schizophrenia. In contrast, the degree of NAc involvement is unknown and recent studies have suggested that PCP-induced hyperactivity in rodents may correlate with PFC, rather than NAc, dopamine levels. Rats were treated with 5-20 mg/kg/day PCP for 3- 14 days by osmotic minipump. PFC and NAc dopamine release to amphetamine challenge ( I mg/kg) was monitored by in vivo microdialysis and HPLC-EC. Doses of $10 \mathrm{mg} / \mathrm{kg} /$ day and above produced serum PCP concentrations (50- $150 \mathrm{ng} / \mathrm{ml}) \mathrm{most}$ associated with PCP psychosis in humans. PCP-treated rats showed significant, dose-dependent enhancement in amphetamine-induced dopamine release in PFC but not NAc, along with significantly enhanced locomotor activity. Enhanced response was observed following 3-day, as well as 14-day, treatment and resolved within 4 days of PCP treatment withdrawal. These findings support the concept that endogenous NMDA receptor dysfunction could account for the pattern of dopaminergic dysfunction observed in schizophrenia, and suggest that even short duration abuse of PCP-like agents may greatly potentiate behavioral effects of psychostimulants in drug abuse situations. Finally, these studies provide a model system in which to evaluate effects of potential psychotherapeutic agents.

Neuropsychopharmacology (2003) 28, 34-44. doi: I0.1038/sj.npp. 1300019

Keywords: phencyclidine; glutamate; NMDA receptor; amphetamine; dopamine; frontal cortex

\section{INTRODUCTION}

Schizophrenia is a widely prevalent neuropsychiatric disorder of unknown etiology. Symptoms of schizophrenia are divided into three main clusters: positive symptoms, such as paranoia and agitation; negative symptoms, such as anhedonia and emotional withdrawal; and disorganized symptoms, such as formal thought disorder and bizarre behavior (Grube et al, 1998). Positive and disorganized symptoms typically fluctuate in severity over the course of the illness and increase during times of psychotic decompensation (Arndt et al, 1995; Gupta et al, 1997). In contrast, negative symptoms and associated cognitive deficits remain more stable and contribute particularly to poor long-term outcome (Gold et al, 1999; O'Leary et al, 2000).

*Correspondence: DC Javitt, Cognitive Neuroscience, Schizophrenia Division, Nathan Kline Institute for Psychiatric Research, New York University School of Medicine, 140 Old Orangeburg Road, Orangeburg, NY 10962, USA. Tel: + | 845398 6534, Fax: + | 845398 6545, E-mail: javitt@nki.rfmh.org

Received 19 February 2002; revised 29 April 2002; accepted 29 May 2002
There are at present two major neurochemical theories of schizophrenia. The dopamine hypothesis is based on the observation that amphetamine and other dopaminergic agents induced symptoms that closely resemble those of schizophrenia. Further, dopamine (D2) receptor antagonists are therapeutically antipsychotic. This model has been supported recently by in vivo neuroimaging studies showing enhanced subcortical dopamine release in response to amphetamine challenge in individuals with schizophrenia (Abi-Dargham et al, 1998; Breier et al, 1997; Laruelle, 1998; Laruelle et al, 1996, 1999). However, amphetamine-induced responses exacerbate only the positive symptoms of schizophrenia. Thus, dopaminergic hyperactivity, of itself, cannot account for the negative or disorganized features of the disorder (Carlsson, 1988).

In contrast, the $\mathrm{N}$-methyl-D-aspartate (NMDA) hypothesis is based upon the observation that phencyclidine (PCP), ketamine, MK-801 and other NMDA antagonists also induce symptoms closely resembling those of schizophrenia (Javitt and Zukin, 1991). These agents uniquely induce symptoms resembling the negative and disorganized symptoms of schizophrenia and produce schizophrenia- 
like information processing deficits by interacting with cortical NMDA receptors (Krystal et al, 1994; Lahti et al, 1995; Malhotra et al, 1996; Umbricht et al, 2000). However, it remains unknown whether NMDA receptor dysfunction, of itself, would be sufficient to account for the dopaminergic hyperactivity associated with the disorder. The present study investigates the hypothesis that persistent NMDA dysfunction may lead to secondary dysregulation of frontal/ limbic dopaminergic neurotransmission, using a combined in vivo microdialysis and behavioral approach. We have previously evaluated the effects of subchronic PCP administration on amphetamine-induced dopamine release in the striatum (Balla et al, 2001b). The present study focuses on prefrontal cortex (PFC) and nucleus accumbens (NAc) shell regions that are postulated to play a crucial role in mediating the behavioral effects of increased dopaminergic activity in schizophrenia (Bertolino et al, 2000; Grace, 2000; Jentsch and Roth, 1999; Lewis et al, 1999; Selemon and Goldman-Rakic, 1999).

In addition to being associated with increased sensitivity to amphetamine-induced dopamine release, schizophrenia is associated with increased susceptibility to disorganizing effects of amphetamine (Szeszko et al, 1999). In order to model this aspect of the disorder, effects of subchronic, continuous PCP treatment on amphetamine-induced locomotor hyperactivity were monitored as well. Finally, the time course of dopamine release in PFC and NAc was compared to the time course of amphetamine-induced locomotor activity in order to evaluate the relative contributions of PFC and NAc to PCP-induced enhancement of sensitivity to amphetamine challenge.

\section{MATERIALS AND METHODS}

\section{Animals}

Studies were carried out in accordance with the Guide for the Care and Use of Laboratory Animals as adopted and promulgated by the National Institutes of Health. Male Sprague-Dawley rats (150-200 g) were bred in-house. Animals were maintained under a $10 \mathrm{~h} / 14 \mathrm{~h}$ dark/light cycle, and were allowed food and water ad libitum during the microdialysis procedure and during the nighttime locomotor activity measurements. Food was withdrawn during amphetamine challenge procedures. In all, three to nine animals were used per group.

\section{PCP Administration}

PCP hydrochloride (obtained from the National Institute of Drug Abuse) was dissolved in sterile physiological saline and administered via an osmotic pump (ALZA Corporation, model 2ML4) implanted under the skin. Saline-filled pumps were used in control animals. The pumps were filled based on animal weight at the start of the experiment to deliver 5, 10,15 or $20 \mathrm{mg} / \mathrm{kg} /$ day for indicated time intervals. The implantation was carried under anesthesia with ketamine hydrochloride and acepromazine maleate 1:1 mixture ( $1 \mu \mathrm{l} / \mathrm{g}$ i.m.). Amphetamine sulfate (RBI) was dissolved in distilled water and was given subcutaneously at $1 \mathrm{mg} / \mathrm{kg}$ dose.

\section{Microdialysis}

Microdialysis was performed 3-22 days following pump implantation. Animals were anesthetized with chloral hydrate $(400 \mathrm{mg} / \mathrm{kg}$ i.p.) and mounted in a stereotaxic frame (David Kopf Instrument). CMA 10 guide cannulae (Carnegie Medicine) were implanted into medial PFC (AP: +4.1, L: +1.0, V: -1.2 ) and/or NAc (AP: +1.70, L: $0.8, \mathrm{~V}:-8.00)$ according to the atlas of Paxinos and Watson (1998) on the day prior to the microdialysis experiment. Implantation coordinates were determined relative to bregma. PFC cannulae were inserted at an AP angle of $20^{\circ}$ relative to skull surface. Cannulae were cemented to the skull using dental acrylic with embedded stainless-steel bone screws.

The day following surgery, CMA 10 probes with $0.5 \mathrm{~mm} \times 2.0(\mathrm{NAc})$ or $4.0 \mathrm{~mm}$ (PFC) membrane length with a molecular cut-off $20000 \mathrm{Da}$ were inserted into the guide cannulae. The estimated probe recovery rate was $18-20 \%$. Probes were continuously perfused using a syringe pump CMA/100 (Carnegie Medicine) at a flow rate of $1.0 \mu \mathrm{l} / \mathrm{min}$ with an $\mathrm{Mg}^{2+}$-free Ringer solution containing $\mathrm{NaCl} 147 \mathrm{mM}$; $\mathrm{KCl} 4 \mathrm{mM} ; \mathrm{CaCl}_{2} 1.2 \mathrm{mM}$ (degassed). The time allowed to establish the basal level of the extracellular catecholamines was $2 \mathrm{~h}$ and, 30-min dialysate samples were collected with a fraction collector (Bioanalytical Systems). After three baseline samples, the rats were challenged with an amphetamine injection (1 mg/kg s.c.). Dialysis samples were collected for an additional $210 \mathrm{~min}$.

\section{Dopamine, DOPAC and HVA Level Determinations}

Dopamine and dopamine metabolite levels were determined by high-pressure liquid chromatography with electrochemical detection (HPLC-EC) (BAS-480 system). The dialysate samples $(30 \mu \mathrm{l})$ - collected in $0.1 \mathrm{~N}$ perchloric acid - were injected by an autosampler (BAS Sample Sentinel) on to a microbore $\mathrm{C}_{18} 100 \times 2 \mathrm{~mm}$ column. The sample was eluted with filtered, degassed mobile phase $\left(\mathrm{NaH}_{2} \mathrm{PO}_{4} 25 \mathrm{mM}\right.$; sodium citrate $50 \mathrm{mM}$; disodium-EDTA $27 \mu \mathrm{M}$; diethylamine-HCl $10 \mathrm{mM}$; 1-octanesulfonic acid $2.2 \mathrm{mM}$, methanol $3 \% \mathrm{v} / \mathrm{v}$; dimethylacetamide $2.1 \% \mathrm{v} / \mathrm{v} ; \mathrm{pH}=3.5$ ) at a flow rate of $0.4 \mathrm{ml} / \mathrm{min}$. Classic glassy carbon electrodes (BAS) $v s$ $\mathrm{Ag} / \mathrm{AgCl}$ reference electrode at 0.60 and $0.75 \mathrm{~V}$ and with sensitivity levels of 0.2 and $20 \mathrm{nA}$ were used for dopamine and DOPAC/HVA determinations, respectively. Retention times for DOPAC, dopamine and HVA were 3.8, 4.9 and $7.8 \mathrm{~min}$, respectively.

Data were acquired on a PC-compatible computer using BAS-5 interface. Standard curves were constructed using 8 points between 0.625 and $80 \mathrm{pg} / 10 \mu \mathrm{l}$ for dopamine, 23.4$3000 \mathrm{pg} / 10 \mu \mathrm{l}$ for DOPAC and $15.62-2000 \mathrm{pg} / 10 \mu \mathrm{l}$ for HVA. Correlation coefficients $(r)$ of $>0.98$ were obtained for all curves. The working standard solutions were stored at $-80^{\circ} \mathrm{C}$ and $10 \mu \mathrm{l}$ of the standard solution was injected between biological samples.

\section{PCP Analysis and Determination of the Probe Placement}

On the day following the microdialysis study, the rats were anesthetized with ketamine hydrochloride and acepromazine maleate $1: 1$ mixture $(1 \mu \mathrm{l} / \mathrm{g}$ i.m.). A heart-punctured 

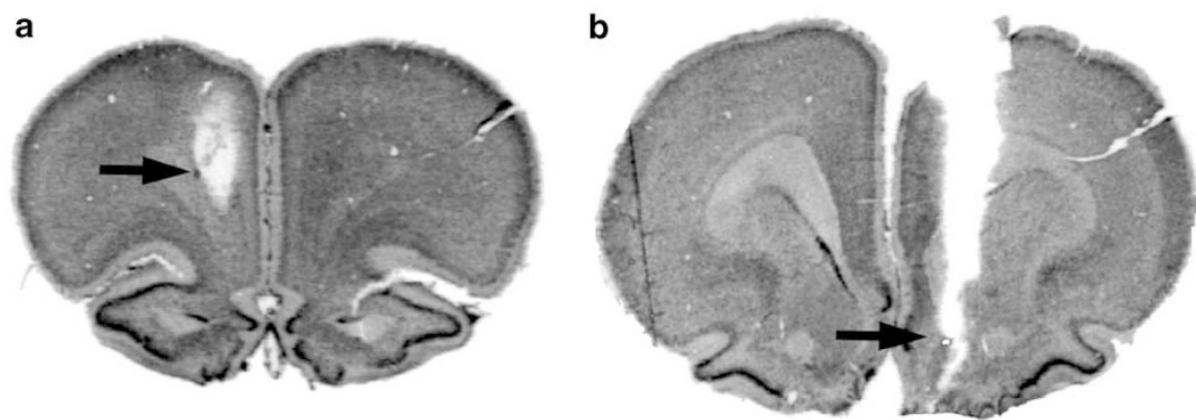

Figure I Photomicrograph showing probe placement in PFC (a) and NAc shell (b).

blood sample was taken. The blood was spinned down and the serum was used for PCP analysis. The rat brain was fixed with $4 \%$ formaldehyde solution perfused through the heart; the brain was stored in a $30 \%$ glucose solution. The placement of the probes was determined histologically (Figure 1).

\section{Locomotor Activity}

Spontaneous and amphetamine-induced locomotor activity (total activity counts) was monitored using an automated infrared beam-based system (Columbus Instrument AutoTrack). All testing was performed in animals' home cages. For assessment of spontaneous activity, animals were placed on activity monitors overnight, and activity was measured at $60 \mathrm{~min}$ intervals. For monitoring of the amphetamineinduced activity, animals were placed on the monitors and baseline activity was monitored for $30 \mathrm{~min}$. Animals then received amphetamine ( $1 \mathrm{mg} / \mathrm{kg}$ s.c), following which activity was monitored for $210 \mathrm{~min}$. Spontaneous nighttime activity measurements were obtained pre-implantation of PCP containing minipumps and at 1 and 2 weeks following minipump insertion. The amphetamine-induced activity was monitored pre-implantation and following continuous ( 2 week) treatment with PCP or saline. Activity measures were obtained at least $48 \mathrm{~h}$ prior to microdialysis studies.

\section{Data Analysis}

Primary-dependent measures consisted of dopamine levels prior to and following amphetamine administration and amphetamine-induced locomotor activity. DOPAC and HVA levels and spontaneous nighttime activity served as additional explanatory variables. Data were analyzed using repeated measures ANOVA with Huynh-Feldt correction for nonsphericity (SPSS for Windows, SPSS, Inc., Chicago, IL, USA) and with within-subject factor of time following amphetamine injection (ie, fraction or observation number) and between-subject factor of drug (PCP or saline). Significant main or interaction effects were followed up by between-group post hoc $t$-test. All statistics are two-tailed with preset $\alpha$ level of significance of $p<0.05$. Data in text are mean \pm SEM.

\section{RESULTS}

\section{PCP Blood Levels}

PCP treatment led to a dose-dependent increase in serum PCP levels (Figure 2). An important consideration in the use of subchronic PCP models is that appropriate doses should be used. Although several prior studies have utilized subchronic dosing regiments, none has determined serum levels during chronic infusion. Walberg et al (1983) have demonstrated that PCP-induced psychosis is most associated with serum concentrations of up to $200 \mathrm{ng} / \mathrm{ml}$. Serum concentrations obtained in this study were thus in the range most associated with PCP-induced psychosis, catatonia and agitation in humans.

\section{Dopamine Release}

Effects of subchronic continuous PCP treatment were evaluated on basal dopamine levels and amphetamine-induced dopamine release in PFC (Figure 3) and NAc (Figure 4). Basal levels were obtained over $90 \mathrm{~min}$ after a $2 \mathrm{~h}$ stabilization period. Following amphetamine administration, release was monitored for an additional $210 \mathrm{~min}$.

Prefrontal cortex In control animals, amphetamine induced a significant elevation in dopamine levels that peaked at $90 \mathrm{~min}$ and returned to baseline at 210 min. PCP treatment did not significantly affect the basal levels of dopamine, at any of the doses tested, although there was a trend toward increase in the $15 \mathrm{mg} / \mathrm{kg} /$ day condition (Figure 3). Basal DOPAC and HVA levels were significantly higher in animals treated with $20 \mathrm{mg} / \mathrm{kg} /$ day PCP than in controls $(t=2.32, \mathrm{df}=11$, $p<0.05)$.

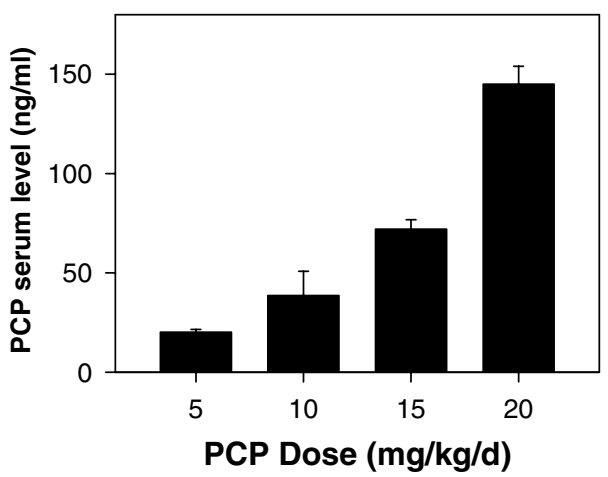

Figure 2 PCP serum levels at indicated doses after 2 weeks of continuous PCP treatment. Data are mean \pm SEM ( $n=5-7$ per group). 
PREFRONTAL CORTEX
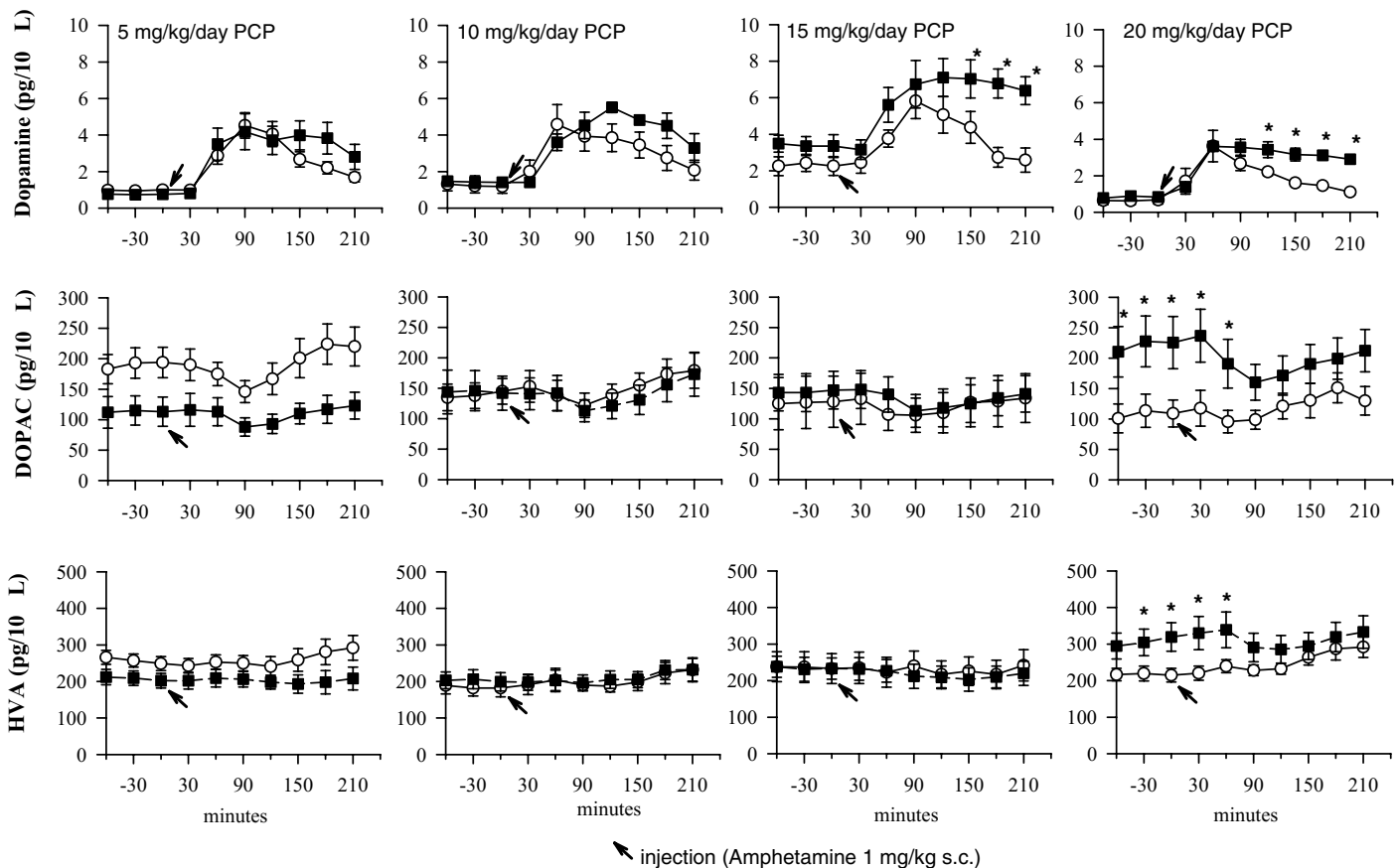

Figure 3 Amphetamine-induced alterations in dopamine, DOPAC and HVA levels from PFC in animals that had been treated for 2 weeks with PCP ( or saline $(\mathrm{O})$ at indicated doses. Amphetamine $(\mathrm{I} \mathrm{mg} / \mathrm{kg}$ ) was administered at time 0 (arrow). Data are mean $\pm \mathrm{SEM}(n=5-8$ per group). * $p<0.05 \mathrm{vs}$ saline.

The primary consequence of PCP treatment was a significant, dose-dependent increase in amphetamineinduced stimulation release throughout the $0-210 \mathrm{~min}$ postinjection interval. This was manifest across dose levels as a significant main effect of PCP treatment $(\mathrm{F}=5.99, \mathrm{df}=1,41, \quad p<0.001)$ and a significant main effect of dose level $(\mathrm{F}=6.54, \mathrm{df}=3,41, p=0.001)$. There were also highly significant treatment $\times$ time $(F=9.18$, $\mathrm{df}=4.3,246, \quad p<0.001) \quad$ and dose $\times$ time $\quad(\mathrm{F}=3.08$, $\mathrm{df}=13,246, \quad p<0.001)$ interactions, indicating that the effects of PCP were more robust late $(120-210 \mathrm{~min})$ than early (0-120 min) following amphetamine administration (Figure 3).

Follow-up ANOVAs were conducted at each dose level independently. No significant main effect of PCP treatment $(\mathrm{F}=0.93, \mathrm{df}=1,10, p=0.4)$ or $\mathrm{PCP}$ treatment $\times$ time interaction $(\mathrm{F}=1.59, \mathrm{df}=4.7,60, \quad p=0.2)$ was observed following treatment with $5 \mathrm{mg} / \mathrm{kg} /$ day PCP. However, a significant $\mathrm{PCP} \times$ time interaction was observed following treatment with $10 \mathrm{mg} / \mathrm{kg} /$ day $(\mathrm{F}=3.34, \mathrm{df}=5.2,48, p=0.01)$ owing to relatively elevated dopamine release in the PCP condition during the 120$210 \mathrm{~min}$ period. Following treatment with either 15 or $20 \mathrm{mg} / \mathrm{kg} /$ day PCP, there were significant main effects of both PCP treatment $(15 \mathrm{mg} / \mathrm{kg} /$ day: $\mathrm{F}=4.7, \mathrm{df}=1,12$, $p=0.05 ; 20 \mathrm{mg} / \mathrm{kg} /$ day: $\mathrm{F}=5.1, \mathrm{df}=1,11, p=0.05)$ and significant PCP X treatment interactions $(15 \mathrm{mg} / \mathrm{kg} /$ day: $\mathrm{F}=2.92, \quad \mathrm{df}=3.6,72, \quad p=0.04 ; \quad 20 \mathrm{mg} / \mathrm{kg} / \mathrm{d}: \quad \mathrm{F}=4.64$, $\mathrm{df}=2.7,66, p=0.01)$. Post hoc $t$-tests revealed significant between-group differences throughout the 120-210 min post-treatment interval in both the 15 and $20 \mathrm{mg} / \mathrm{kg} /$ day conditions.
NUCLEUS ACCUMBENS SHELL
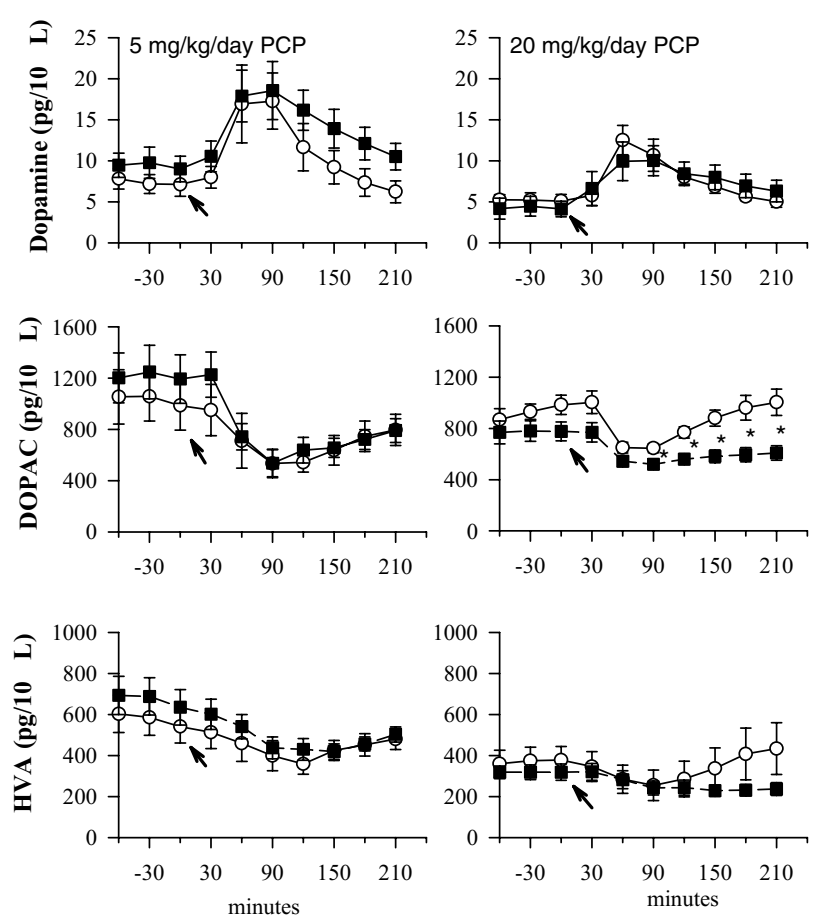

V injection (Amphetamine 1mg/kg s.c.)

Figure 4 Amphetamine-induced alterations in dopamine, DOPAC and HVA levels from NAc (shell) in animals that had been treated for 2 weeks with PCP $(\boldsymbol{\square})$ or saline $(\mathrm{O})$ at indicated doses. Amphetamine $(\mathrm{I} \mathrm{mg} / \mathrm{kg})$ was administered at time 0 (arrow). Data are mean \pm SEM ( $n=5-7$ per group). ${ }^{*} p<0.05$ vs saline. 
Nucleus accumbens In control animals, amphetamine induced a highly significant three-fold increase in dopamine levels that peaked at $90 \mathrm{~min}$ and returned to baseline by $210 \mathrm{~min}$. The increase in dopamine levels was associated with significant decreases in DOPAC and HVA levels during the 150-210 min period (Figure 4). PCP treatment did not significantly affect basal levels of dopamine, DOPAC or HVA following either low- or high-dose administration. Further, no significant between-group differences in dopamine levels were observed following amphetamine administration (Figure 4). Treatment with high-dose PCP did, however, lead to significant potentiation of the DOPAC response to amphetamine administration, such that levels remained significantly reduced during the late postamphetamine administration period.

\section{Behavior}

Two measures of behavior were obtained. Amphetamineinduced activity was monitored in order to evaluate the relationship between alterations in dopamine levels and known chronic PCP-induced potentiation of amphetamineinduced locomotor activity (Jentsch et al, 1998a). Activity measurements were obtained for $210 \mathrm{~min}$ following amphetamine administration. Total nighttime activity was monitored in order to evaluate PCP effects on spontaneous behavior and to control for possible ataxia-induced decreases in locomotion. Behavior was monitored throughout the $4 \mathrm{pm}$ to $8 \mathrm{am}$ period, which is the interval of peak activity for rodents with non-reversed day/night cycles.

PCP treatment led to a highly significant, dose-dependent potentiation of amphetamine-induced locomotor activity at all doses tested (Figure 5a, post-treatment). Amphetamine increased locomotor activity starting $30 \mathrm{~min}$ after injection, coming back to baseline around $150-180 \mathrm{~min}$ after the injection. A significant PCP-dose-dependent prolongation in amphetamine-induced ( $1 \mathrm{mg} / \mathrm{kg}$ s.c.) locomotor activity was observed after chronic continuous PCP administration, giving curves that resembled the PFC dopamine curves. PCP
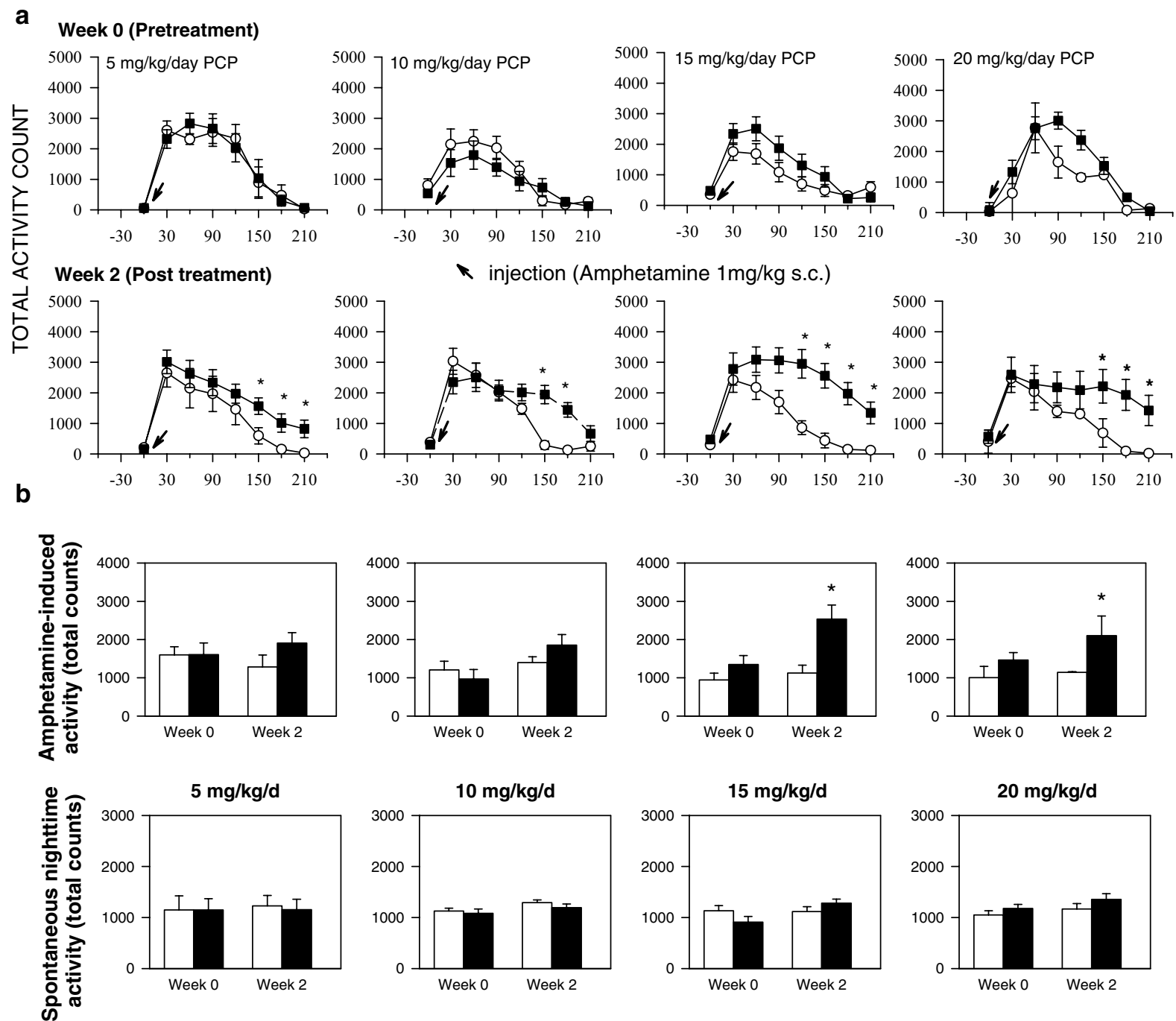

Figure 5 (a) Amphetamine-induced total locomotor activity as a function of time following amphetamine administration prior to (week 0 , top) and following (week 2, bottom) 2-week treatment with PCP $(\mathbf{\square})$ or saline $(O) .{ }^{*} p<0.05$ vs saline. (b) Averaged amphetamine-induced total locomotor activity over the 0-210 min period (top) and averaged spontaneous nighttime activity (4 pm to $8 \mathrm{am}$ ) (bottom) at indicated dose levels prior to (week 0 ) and following (week 2) PCP (filled bars) or saline (open bars) administration. 
effects on amphetamine-induced hyperactivity were highly dose-dependent (Figure 5a). In contrast to amphetamineinduced activity, spontaneous nighttime activity was not significantly increased at any of the doses tested (Figure 5b). Thus, the enhancement of activity reflects specific enhancement of amphetamine-induced effect rather than generalized hyperexcitability.
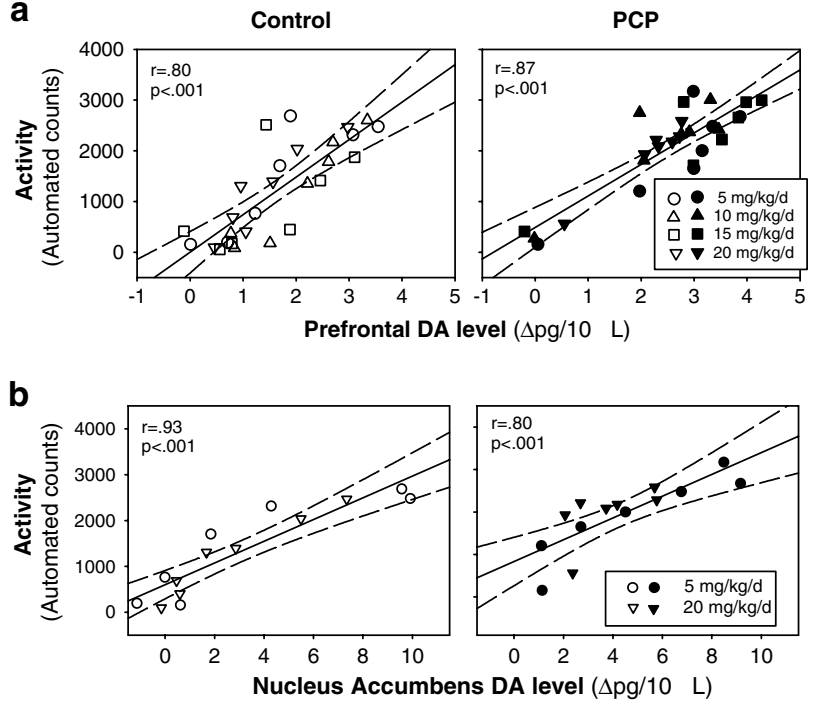

Figure 6 Scatter plots showing the relationship between increase in dopamine levels over time following amphetamine administration vs increase in locomotor activity. Top graphs represent dopamine data from PFC (shown in Figure 3) vs behavioral data (shown in Figure 5a). Bottom graphs represent data from NAc (shown in Figure 4) vs behavioral data. In both cases, dopamine level data are lagged I fraction (30 min) relative to behavioral data to allow for transit time in dialysis tubing and delay between neurochemical and behavioral changes. Open symbols represent data from saline-treated animals (control). Filled circles represent data from animals treated for 2 weeks with PCP. Pearson linear regression coefficient $(r)$ are shown along with corresponding probably $(p)$ values.

\section{Correlation Between Dopamine Microdialysate and Behavior Measures}

Both amphetamine- and PCP-induced hyperactivity have traditionally been associated with alterations in dopamine release within NAc (Clarke et al, 1988; French and Vantini, 1984; Jentsch et al, 1998a; Kelley and Throne, 1992; McCullough and Salamone, 1992; Nabeshima et al, 1983; Ouagazzal et al, 1994). Recently, it has been demonstrated that increased PFC dopamine levels also correlate with the time course of hyperactivity following PCP administration (Adams and Moghaddam, 1998). The relationship between amphetamine-induced dopamine release in PFC and locomotor hyperactivity, however, has been relatively less studied.

In order to investigate relationships between dopamine release in PFC and NAc and amphetamine-induced locomotor hyperactivity in both control and PCP-treated animals, two sets of correlational analyses were conducted. The first investigated the relationship between dopamine levels and locomotor activity across time within each condition (Figure 6). The second investigated summed activity over the $0-210 \mathrm{~min}$ postamphetamine-treatment interval across conditions (Figure 7). For both PFC and NAc, significant correlations were observed between amphetamine-induced alterations in dopamine levels and locomotor hyperactivity in both control and PCP-treated animals (Figure 6). However, when analyses were conducted using summed activity and DA levels over the $0-210 \mathrm{~min}$ interval to investigate the basis for enhanced amphetamineinduced locomotor activity in PCP-treated animals, a significant correlation was observed only for PFC (Figure 7), indicating that the enhanced locomotor activity observed following subchronic, continuous PCP administration was related to enhanced amphetamine-induced activity within PFC, rather than NAc.

\section{Dopaminergic Hyperactivity Following Shorter Term PCP Treatment}

The primary PCP treatment interval was 2 weeks, which permitted the assessment of amphetamine-induced
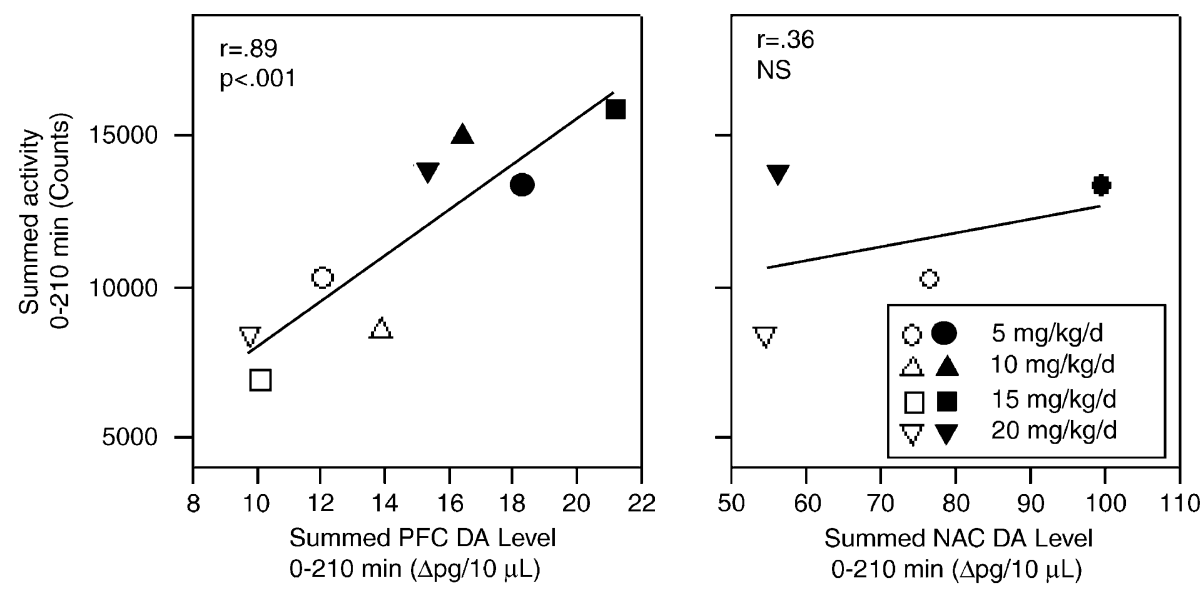

Figure 7 Scatter plots showing relationship between summed total activity counts following amphetamine administration vs summed dopamine (DA) release over baseline for animals treated with PCP or saline for 2 weeks at indicated dosage levels. Open symbols represent data from saline-treated control animals. Filled symbols represent data from PCP-treated animals. Pearson linear regression coefficient $(r)$ are shown along with corresponding probably ( $p$ ) values. Note significant correlation in data from prefrontal cortex (PFC, left panel) but not from nucleus accumbens (NAc, right panel). 
hyperactivity without confounding the effects of PCPinduced ataxia or sedation. Although the 2-week subchronic treatment interval led to robust increases in amphetamineinduced dopamine release along with the expected increases in amphetamine-induced hyperactivity, it remained unclear whether the 2-week treatment interval was required. In order to evaluate whether long-term treatment is, indeed, required, an additional group of animals was treated for 3 days prior to microdialysis (Figure 8a). This is the minimum length of time required for recovery from minipump implantation prior to amphetamine challenge.

As with the 2 -week treatment, 3 -day $(20 \mathrm{mg} / \mathrm{kg} /$ day $)$ treatment led to a significant potentiation of amphetamine-induced dopamine release during the $90-210 \mathrm{~min}$ postamphetamine interval, resulting in a highly significant main effect of PCP treatment $(\mathrm{F}=48.6, \mathrm{df}=1,4, p=0.002)$ and a significant PCP $X$ time interaction $(F=7.98$, $\mathrm{df}=2.0,24, p=0.01)$ (Figure $8 \mathrm{a}$ ).

\section{Dopaminergic Hyper-reactivity Following PCP Withdrawal}

A final set of experiments evaluated the degree to which dopaminergic hyper-reactivity in PFC persisted following PCP discontinuation. For this experiment, animals received
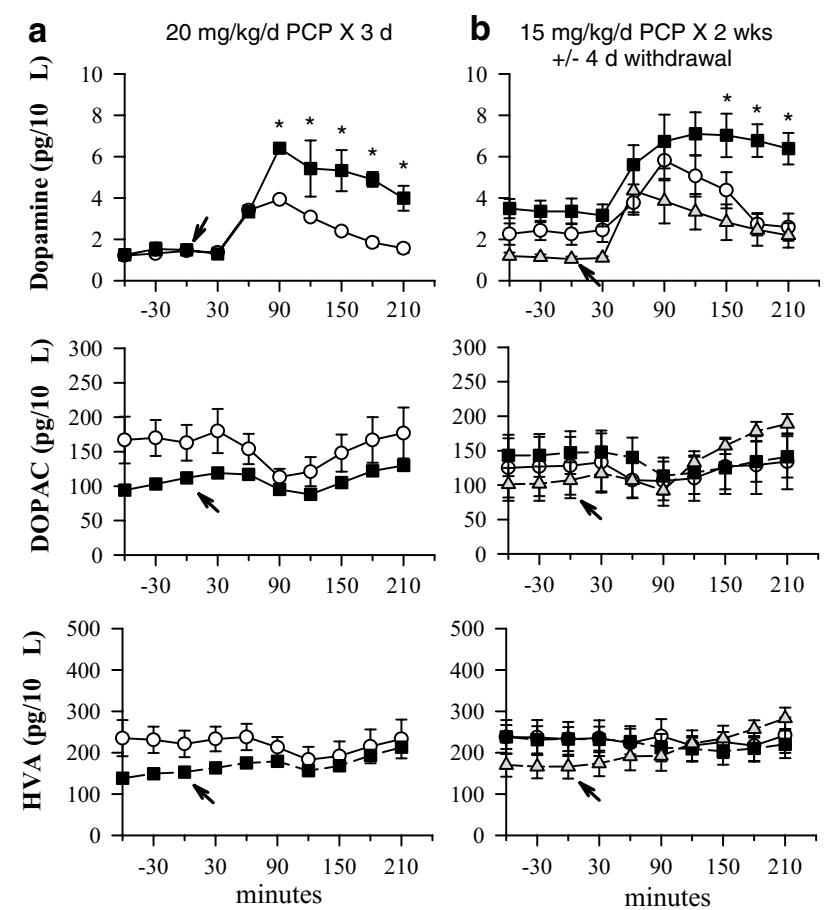

injection (Amphetamine 1mg/kg s.c.)

Figure 8 (a) Amphetamine-induced changes in dopamine, DOPAC and HVA levels from prefrontal cortex after 3-day treatment with $20 \mathrm{mg} / \mathrm{kg} /$ day PCP (ם) or saline (O) ( $n=3-4$ per group). (b) Amphetamine-induced changes in dopamine, DOPAC and HVA levels from prefrontal cortex in animals treated for 2 weeks with $15 \mathrm{mg} / \mathrm{kg} / \mathrm{day} \mathrm{PCP}$ and then withdrawn for 4 days $(\triangle)$ vs animals treated for 2 weeks and not withdrawn $(\boldsymbol{\square})$ or 2 week saline-treated controls $(O)(n=4-6$ per group). Data from the nonwithdrawn and saline control groups are from Figure 2 and are reproduced for comparison purposes. a dose of $15 \mathrm{mg} / \mathrm{kg} /$ day PCP for 2 weeks, whereupon the minipumps were removed. Amphetamine challenge tests were conducted 4 days following minipump removal. Values were compared both to those of animals who received amphetamine challenge prior to minipump removal and to control animals (Figure $8 \mathrm{~b}$ ).

Dopamine levels obtained when amphetamine challenge was conducted 4 days following minipump removal were significantly lower than that obtained when challenge was conducted while the animals were still receiving PCP $(\mathrm{F}=5.66, \mathrm{df}=1,10, p=0.4)$. The differences were most pronounced during the $150-210 \mathrm{~min}$ interval, $\mathrm{q}$ resulting also in a significant condition $X$ time interaction $(\mathrm{F}=3.53, \mathrm{df}=3.0,60, p=0.03)$. In contrast, levels 4 days following pump removal were not significantly different from control values $(\mathrm{F}=0.7, \mathrm{df}=1,6, p=0.5)$. Summed amphetamine-induced dopamine release following pump removal $(21.6 \pm 9.4 \mathrm{pg})$ was significantly lower $(t=2.38, \mathrm{df}=10, p=0.04)$ than release in animals still receiving PCP $(40.7 \pm 12.6 \mathrm{pg})$ but not significantly different from release in control animals $(26.8 \pm 8.6 \mathrm{pg}, t=0.8$, $\mathrm{df}=6, p=0.5)$.

\section{DISCUSSION}

Effects of amphetamine and NMDA antagonists on dopamine release in cortical and limbic brain regions have been extensively characterized following single administration of either agent. In contrast, the effects of combined administration have not. This is the first study to investigate the effects of subchronic PCP treatment on amphetamineinduced dopamine release in PFC. There are several major findings of this study. First, this study demonstrates that subchronic continuous treatment with PCP results in sustained hyper-responsivity of dopaminergic neurotransmission in PFC to the effects of amphetamine. The effects of $\mathrm{PCP}$, since they are regionally specific, cannot be ascribed to dopamine transport inhibiting properties of PCP (Nishijima et al, 1996). Second, PCP-induced increases in behavioral responsivity to amphetamine, which have been reported previously, were found to be unrelated to increased dopamine release in NAc, but were related to increased dopamine release within PFC. Finally, following PCP withdrawal, dopaminergic hyper-reactivity resolved within days, suggesting that NMDA blockade itself, rather than secondary adaptations, were responsible for the dopaminergic hyper-responsivity to amphetamine.

Serum PCP levels in this study were similar to those observed during clinical PCP intoxication in humans. PCP doses of $10-20 \mathrm{mg} / \mathrm{kg} /$ day in rodents have also been found to be effective by other groups (Jentsch et al, 1998a; Martinez et al, 1999; Sams-Dodd, 1998). Ehrhardt et al (1999) found no significant effect of $5 \mathrm{mg} / \mathrm{kg} /$ day PCP, similar to the observations in the present study.

\section{Effects of Subchronic, Continuous PCP Administration on Basal Dopamine Levels}

Acute PCP administration induces a well-described stimulation of dopamine release within PFC and NAc (Adams and Moghaddam, 1998; Javitt et al, 1999; Kato et al, 2000; McCullough and Salamone, 1992). The duration over which 
these elevated levels are sustained during continuous treatment, however, remains unknown. In the present study, no significant sustained elevations in basal dopamine release were observed following either 3-day or 2-week PCP treatment at any of the doses tested. Therefore, it appears that tolerance is reached to the acute dopamine-releasing effects of phencyclidine within a 3-day period.

Results of this study are consistent with those of several prior investigations. For example, Jentsch et al (1998a) found no significant alterations in absolute PFC dopamine levels 1 or 3 weeks following a 7-day subchronic treatment with $10 \mathrm{mg} / \mathrm{kg} /$ day PCP, although the DOPAC/dopamine ratio was altered. Similarly, Lannes et al (1991) found no change in tissue levels of dopamine or DOPAC following a 60 -day treatment repeatedly with $15 \mathrm{mg} / \mathrm{kg} /$ day ketamine administered orally, despite the fact that animals showed increased behavioral sensitivity to both apomorphine and haloperidol. In contrast, Lindefors et al (1997) observed increased extracellular dopamine levels in PFC in animals treated intermittently with $25 \mathrm{mg} / \mathrm{kg}$ ketamine daily for 7 days. Reasons for the differential results need to be determined.

A third finding of this study is that the effects of subchronic PCP treatment on dopamine release were regionally selective. We (Balla et al, 2001b) and others (Miller and Abercrombie, 1996) have previously observed potentiation of striatal dopamine release following administration of NMDA antagonists. However, this is the first study to demonstrate a similar phenomenon in PFC and the absence of such a phenomenon in NAc shell.

Although the present study did not find alterations in basal dopamine levels at any dose, basal DOPAC levels were significantly elevated following a 7-day treatment with $20 \mathrm{mg} / \mathrm{kg} /$ day PCP. This may indicate increased dopamine turnover even in the absence of elevated dopamine levels, and supports the finding of Jentsch et al (1998a) concerning the effects of subchronic PCP administration on tissue dopamine turnover.

\section{Regionally Specific Effects of PCP on Dopamine Response to Amphetamine}

Based upon the present results, two issues need to be discussed. First, why NMDA receptor antagonist administration potentiates amphetamine-induced dopamine release at all, and second, why potentiation is observed in PFC and striatum, but not in NAc. One potential site of action of PCP may be at NMDA receptors located on GABA interneurons within PFC. NMDA receptors in the PFC inhibit tonic dopamine release (Hata et al, 1990), so that local application of NMDA antagonists into PFC increases local dopamine levels (Hondo et al, 1994; Nishijima et al, 1996; Yonezawa et al, 1998). Chronic PCP treatment, however, increases the sensitivity of GABA interneurons to NMDA stimulation (Hanania and Johnson, 1999) and induces the upregulation of NR1 subunit expression (Wang et al, 1999). These adaptive changes may contribute to the absence of a sustained dopamine elevation during continuous PCP treatment. In a prior study, we did not observe an enhancement of dopamine response to locally administered amphetamine in the frontal cortex of PCP-treated animals (Balla et al, 2001a), consistent with the findings of Miller and Abercrombie (1996). This finding suggests that the enhancement in amphetamine-induced release is not because of the modulation of local circuitry within the cortex, but may represent impaired interaction between brain regions.

NMDA receptors also exert tonic control over dopamine release in NAc via the modulation of local circuit, GABAergic interneurons (Doherty and Gratton, 1997; Taber et al, 1996). Thus, local circuit mechanisms of themselves, would not explain the differential effects of subchronic continuous PCP treatment in PFC vs NAc. One potential explanation for the regional selectivity is the existence of corticoaccumbens fibers originating in PFC that exert inhibitory control over dopamine release in NAc (Sesack and Pickel, 1992). These neurons receive direct dopaminergic innervation (Carr et al, 1999). As a result, a reduction in dopamine levels in PFC increases dopamine release in NAc (King and Finlay, 1997; Thompson and Moss, 1995), whereas an increase in dopamine levels in PFC attenuates NAc dopamine release (Doherty and Gratton, 1999). In contrast, dopamine levels in PFC do not appear to regulate the levels in the striatum (King and Finlay, 1995) which is under tonic excitatory control by PFC (Karreman and Moghaddam, 1996). The differential relationship between PFC on the one hand and NAc and striatum on the other may explain the differential effect of subchronic PCP treatment on dopamine release within those two areas.

Another potential site of influence of PCP is on VTA (A10) neurons that project to PFC and NAc. Injection of glutamate into VTA activates dopamine neurons projecting to both PFC and NAC. However, NMDA receptors preferentially modulate neurons projecting to $\mathrm{PFC}$, whereas kinate receptors modulate neurons projecting to NAc (Kalivas et al, 1989; Takahata and Moghaddam, 1998, 2000). Thus, the lack of effect of PCP treatment on NAc dopamine release may be because of the relative insensitivity of mesolimbic (as opposed to mesocortical neurons) to NMDA inhibition.

VTA has been shown to contain a population of NMDAdriven GABAergic neurons that receives input from both PFC and NAc, but returns inhibitory output only to PFC (Steffensen et al, 1998). PCP-induced inhibition of such neurons would be expected, therefore, to lead to selective disinhibition of PFC neurons, relative to NAc. One additional possibility that must be considered is a direct effect of PCP on AMPH metabolism (Hiratsuka et al, 1995). However, such an effect would not account for the regional selectivity of the PCP effect of AMPH-induced dopamine release, nor for the dissociation between behavioral effects and NAc dopamine release.

It has been widely hypothesized that schizophrenia is associated with reduced basal dopamine levels, contributing to impaired performance on prefrontal tasks such as the Wisconsin Card Sorting Test (WCST) (Cohen and ServanSchreiber, 1993; Goldman-Rakic and Selemon, 1997; Grace, 1991; Weinberger and Lipska, 1995). However, the possibility that patients with schizophrenia nevertheless show exaggerated prefrontal response to psychostimulants has not been expressly evaluated. Since the baseline PFC dopamine levels in this study were close to the limit of resolution of the assay, a PCP-induced decrease in basal DA 
levels cannot be excluded. The exaggerated amphetamine response observed in PFC of PCP-treated rodents is consistent with the observation that amphetamine robustly stimulates dorsolateral PFC dopamine release during WCST performance in patients with schizophrenia (Daniel et al, 1991), but not in controls (Mattay et al, 1996), and may be reflective of more general prefrontal dysfunction (Bertolino et al, 2000).

\section{Dissociation between Behavioral Effects and NAc Dopamine Release}

The hyperactivity produced by acute amphetamine administration has traditionally been ascribed to increased dopamine release within NAc (Clarke et al, 1988; Kuczenski et al, 1997; Kuczenski and Segal, 1989), as shown also for control animals in the present study. However, in the present study subchronic PCP treatment substantially increased amphetamine-induced locomotor hyperactivity without altering the NAc dopamine levels, suggesting that the enhancement of activity could not be attributed to increased activity within the mesoaccumbens system. This finding is consistent with the results of both Druhan et al (1996) and Wolf et al (1994), who observed that MK-801 potentiated amphetamine-induced hyperactivity without, itself, inducing dopamine release in NAc or potentiating amphetamine-induced dopamine release. It has recently been suggested that locomotor effects of acutely administered PCP reflect its actions within PFC rather than NAc (Adams and Moghaddam, 1998; Jentsch et al, 1998b) which is consistent with an earlier work of Nabeshima et al (1983). The present study suggests that enhanced amphetamine-induced locomotor activity observed following chronic PCP treatment reflects the actions of PCP within PFC as well.

\section{Implications for Schizophrenia and Drug Abuse}

Symptoms in schizophrenia have long been postulated to reflect cortical and subcortical dopaminergic hyperactivity. However, the mechanisms underlying such dysfunction have been unclear. The results of this and a previous (Balla et al, 2001b) study suggest that ongoing NMDA receptor dysfunction would be sufficient to account for dopaminergic hyperactivity within PFC and striatum. Chronic PCP abuse is associated with cognitive dysfunction that develops during the course of abuse but resolves significantly following discontinuation (Cosgrove and Newell, 1991). Thus, the pattern of cognitive dysfunction in humans exposed to PCP follows the pattern of dopaminergic hyperactivity observed in the present study. The present findings also suggest that even short-duration 'binge'-type abuse of NMDA antagonists, as is seen with ketamine (Jansen, 2000; Weir, 2000), may greatly potentiate behavioral effects of other psychotogenic agents.

\section{ACKNOWLEDGEMENTS}

Supported by USPHS Grant R01 DA03383 and grants from the Burroughs Wellcome Fund and the Zara and Bernad Jakubovitz Memorial Fund for Brain Research to DCJ.

\section{REFERENCES}

Abi-Dargham A, Gil R, Krystal J, Baldwin RM, Seibyl JP, Bowers M et al (1998). Increased striatal dopamine transmission in schizophrenia: confirmation in a second cohort. Am J Psychiatry 155: 761-767.

Adams B, Moghaddam B (1998). Corticolimbic dopamine neurotransmission is temporally dissociated from the cognitive and locomotor effects of phencyclidine. J Neurosci 18: 55455554.

Arndt S, Andreasen NC, Flaum M, Miller D, Nopoulos P (1995). A longitudinal study of symptom dimensions in schizophrenia: Prediction and patterns of change. Arch. Gen. Psychiatry 52: 352360.

Balla A, Hashim A, Burch S, Javitt DC, Lajtha A, Sershen H (2001a). Phencyclidine-induced dysregulation of dopamine response to amphetamine in prefrontal cortex and striatum. Neurochem Res 26: $1001-1006$

Balla A, Koneru R, Smiley J, Sershen H, Javitt DC (2001b). Continuous phencyclidine treatment induces schizophrenia-like hyperreactivity of striatal dopamine release. Neuropsychopharmacology 25: 157-164.

Bertolino A, Esposito G, Callicott JH, Mattay VS, Van Horn JD, Frank JA et al (2000). Specific relationship between prefrontal neuronal $\mathrm{N}$-acetylaspartate and activation of the working memory cortical network in schizophrenia [see comments]. Am J Psychiatry 157: 26-233.

Breier A, Su TP, Saunders R, Carson RE, Kolachana BS, de Bartolomeis A et al (1997). Schizophrenia is associated with elevated amphetamine-induced synaptic dopamine concentrations: evidence from a novel positron emission tomography method. Proc Natl Acad Sci USA 94: 2569-2574.

Carlsson A (1988). The current status of the dopamine hypothesis of schizophrenia. Neuropsychopharmacology 1: 179-186.

Carr DB, O’Donnell P, Card JP, Sesack SR (1999). Dopamine terminals in the rat prefrontal cortex synapse on pyramidal cells that project to the nucleus accumbens. J Neurosci 19: 1104911060 .

Clarke PB, Jakubovic A, Fibiger HC (1988). Anatomical analysis of the involvement of mesolimbocortical dopamine in the locomotor stimulant actions of d-amphetamine and apomorphine. Psychopharmacology 96: 511-520.

Cohen JD, Servan-Schreiber D (1993). A theory of dopamine function and its role in cognitive deficits in schizophrenia. Schizophr Bull 19: 85-104.

Cosgrove J, Newell TG (1991). Recovery of neuropsychological functions during reduction in use of phencyclidine. $J$ Clin Psychol 47: 159-169.

Daniel DG, Weinberger DR, Jones DW, Zigun JR, Coppola R, Handel S et al (1991). The effect of amphetamine on regional cerebral blood flow during cognitive activation in schizophrenia. J Neurosci 11: 1907-1917.

Doherty MD, Gratton A (1997). NMDA receptors in nucleus accumbens modulate stress-induced dopamine release in nucleus accumbens and ventral tegmental area. Synapse 26: 225-234.

Doherty MD, Gratton A (1999). Effects of medial prefrontal cortical injections of GABA receptor agonists and antagonists on the local and nucleus accumbens dopamine responses to stress. Synapse 32: 288-300.

Druhan JP, Rajabi H, Stewart J (1996). MK-801 increase locomotor activity without elevating extracellular dopamine levels in the nucleus accumbens. Synapse 24: 135-146.

Ehrhardt J, Sabel BA, Schroeder U (1999). Subchronically applied phencyclidine fails to disrupt prepulse inhibition in rats. Eur Neuropsychopharmacol 10: 69-74.

French ED, Vantini G (1984). Phencyclidine-induced locomotor activity in the rat is blocked by 6-hydroxydopamine lesion of the 
nucleus accumbens: comparisons to other psychomotor stimulants. Psychopharmacology 82: 83-88.

Gold S, Arndt S, Nopoulos P, O’Leary DS, Andreasen NC (1999). Longitudinal study of cognitive function in first-episode and recent- onset schizophrenia. Am J Psychiatry 156: 1342 1348.

Goldman-Rakic PS, Selemon LD (1997). Functional and anatomical aspects of prefrontal pathology in schizophrenia. Schizophr Bull 23: 437-458.

Grace AA (1991). Phasic versus tonic dopamine release and the modulation of dopamine system responsivity: a hypothesis for the etiology of schizophrenia. Neuroscience 41: 1-24.

Grace AA (2000). Gating of information flow within the limbic system and the pathophysiology of schizophrenia. Brain Res Brain Res Rev 31: 330-341.

Grube BS, Bilder RM, Goldman RS (1998). Meta-analysis of symptom factors in schizophrenia. Schizophr Res 31: $113-120$

Gupta S, Andreasen NC, Arndt S, Flaum M, Hubbard WC, Ziebell S (1997). The Iowa Longitudinal Study of Recent Onset Psychosis: one-year follow-up of first episode patients. Schizophr Res 23: $1-13$.

Hanania T, Johnson KM (1999). Regulation of NMDA-stimulated $[14 \mathrm{C}] \mathrm{GABA}$ and $[3 \mathrm{H}]$ acetylcholine release by striatal glutamate and dopamine receptors. Brain Res 844: 106-117.

Hata N, Nishikawa T, Umino A, Takahashi K (1990). Evidence for involvement of $\mathrm{N}$-methyl-D-aspartate receptors in tonic inhibitory control of dopaminergic transmission in rat medial frontal cortex. Neurosci Lett 120: 101-104.

Hiratsuka A, Chu TY, Distefano EW, Lin LY, Schmitz DA, Cho AK (1995). Inactivation of constitutive hepatic cytochromes P450 by phencyclidine in the rat. Drug Metab Dispos 23: 201-206.

Hondo H, Yonezawa Y, Nakahara T, Nakamura K, Hirano M, Uchimura $\mathrm{H}$ et al (1994). Effect of phencyclidine on dopamine release in the rat prefrontal cortex; an in vivo microdialysis study. Brain Res 633: 337-342.

Jansen KL (2000). A review of the nonmedical use of ketamine: use, users and consequences. J Psychoactive Drugs 32: 419-433.

Javitt DC, Balla A, Sershen H, Lajtha A (1999). A.E. Bennett Research Award. Reversal of phencyclidine-induced effects by glycine and glycine transport inhibitors. Biol Psychiatry 45: 668679.

Javitt DC, Zukin SR (1991). Recent advances in the phencyclidine model of schizophrenia. Am J Psychiatry 148: 1301-1308.

Jentsch JD, Roth RH (1999). The neuropsychopharmacology of phencyclidine: from NMDA receptor hypofunction to the dopamine hypothesis of schizophrenia. Neuropsychopharmacology 20: 201-225.

Jentsch JD, Taylor JR, Roth RH (1998a). Subchronic phencyclidine administration increases mesolimbic dopaminergic system responsivity and augments stress- and psychostimulant-induced hyperlocomotion. Neuropsychopharmacology 19: 105-113.

Jentsch JD, Tran A, Taylor JR, Roth RH (1998b). Prefrontal cortical involvement in phencyclidine-induced activation of the mesolimbic dopamine system: behavioral and neurochemical evidence. Psychopharmacology (Berl) 138: 89-95.

Kalivas PW, Duffy P, Barrow J (1989). Regulation of the mesocorticolimbic dopamine system by glutamic acid receptor subtypes. J Pharmacol Exp Ther 251: 378-387.

Karreman M, Moghaddam B (1996). The prefrontal cortex regulates the basal release of dopamine in the limbic striatum: an effect mediated by ventral tegmental area. J Neurochem 66: 589-598.

Kato K, Shishido T, Ono M, Shishido K, Kobayashi M, Suzuki H et al (2000). Effects of phencyclidine on behavior and extracellular levels of dopamine and its metabolites in neonatal ventral hippocampal damaged rats. Psychopharmacology (Berl) 150: 163-169.
Kelley AE, Throne LC (1992). NMDA receptors mediate the behavioral effects of amphetamine infused into the nucleus accumbens. Brain Res Bull 29: 247-254.

King D, Finlay JM (1995). Effects of selective dopamine depletion in medial prefrontal cortex on basal and evoked extracellular dopamine in neostriatum. Brain Res 685: 117-128.

King D, Finlay JM (1997). Loss of dopamine terminals in the medial prefrontal cortex increased the ratio of DOPAC to DA in tissue of the nucleus accumbens shell: role of stress. Brain Res 767: 192-200.

Krystal JH, Karper LP, Seibyl JP, Freeman GK, Delaney R, Bremner JD et al (1994). Subanesthetic effects of the noncompetitive NMDA antagonist, ketamine, in humans. Psychotomimetic, perceptual, cognitive, and neuroendocrine responses. Arch Gen Psychiatry 51: 199-214.

Kuczenski R, Melega WP, Cho AK, Segal DS (1997). Extracellular dopamine and amphetamine after systemic amphetamine administration: comparison to the behavioral response. $J$ Pharmacol Exp Ther 282: 591-596.

Kuczenski R, Segal D (1989). Concomitant characterization of behavioral and striatal neurotransmitter response to amphetamine using in vivo microdialysis. J Neurosci 9: 20512065.

Lahti AC, Koffel B, LaPorte D, Tamminga CA (1995). Subanesthetic doses of ketamine stimulate psychosis in schizophrenia. Neuropsychopharmacology 13: 9-19.

Lannes B, Micheletti G, Warter J, Kempf E, DiScala G (1991). Behavioral, pharmacological and biochemical effects of acute and chronic administration of ketamine in the rat. Neurosci Lett 128: $177-181$.

Laruelle M (1998). Imaging dopamine transmission in schizophrenia. A review and meta-analysis. Q J Nucl Med 42: 211-221.

Laruelle M, Abi-Dargham A, Gil R, Kegeles LS, Innis R (1999). Increased dopamine transmission in schizoprenia: relationship to illness phases. Biol Psychiatry 46: 56-72.

Laruelle M, Abi-Dargham A, van Dyck CH, Gil R, D'Souza CD, Erdos J et al (1996). Single photon emission computerized tomography imaging of amphetamine-induced dopamine release in drug-free schizophrenic subjects. Proc Natl Acad Sci USA 93: 9235-9240.

Lewis DA, Pierri JN, Volk DW, Melchitzky DS, Woo TU (1999). Altered GABA neurotransmission and prefrontal cortical dysfunction in schizophrenia. Biol Psychiatry 46: 616-626.

Lindefors N, Barati S, O'Connor WT (1997). Differential effects of single and repeated ketamine administration on dopamine, serotonin and GABA transmission in rat medial prefrontal cortex. Brain Res 759: 205-212.

Malhotra AK, Pinals DA, Weingartner H, Sirocco K, Missar CD, Pickar D et al (1996). NMDA receptor function and human cognition: the effects of ketamine in healthy volunteers. Neuropsychopharmacology 14: 301-307.

Martinez ZA, Ellison GD, Geyer MA, Swerdlow NR (1999). Effects of sustained phencyclidine exposure on sensorimotor gating of startle in rats. Neuropsychopharmacology 21: 28-39.

Mattay VS, Berman KF, Ostrem JL, Esposito G, Van Horn JD, Bigelow LB, Weinberger DR (1996). Dextroamphetamine enhances 'neural network-specific' physiological signals: a positron-emission tomography rCBF study. J Neurosci 16: 48164822.

McCullough LD, Salamone JD (1992). Increases in extracellular dopamine levels and locomotor activity after direct infusion of phencyclidine into the nucleus accumbens. Brain Res 577: $1-9$.

Miller DW, Abercrombie ED (1996). Effects of MK-801 on spontaneous and amphetamine-stimulated dopamine release in striatum measured with in vivo microdialysis in awake rats. Brain Res Bull 40: 57-62. 
Nabeshima T, Yamada K, Yamaguchi K, Hiramatsu M, Furukawa $\mathrm{H}$, Kameyama T (1983). Effect of lesions in the striatum, nucleus accumbens and medial raphe on phencyclidine-induced stereotyped behaviors and hyperactivity in rats. Eur J Pharmacol 91: 455-462.

Nishijima K, Kashiwa A, Hashimoto A, Iwama H, Umino A, Nishikawa T (1996). Differential effects of phencyclidine and methamphetamine on dopamine metabolism in rat frontal cortex and striatum as revealed by in vivo dialysis. Synapse 22: $304-312$.

O'Leary DS, Flaum M, Kesler ML, Flashman LA, Arndt S, Andreasen NC (2000). Cognitive correlates of the negative, disorganized, and psychotic symptom dimensions of schizophrenia. J Neuropsychiatry Clin Neurosci 12: 4-15.

Ouagazzal A, Nieoullon A, Amalric M (1994). Locomotor activation induced by MK-801 in the rat: postsynaptic interactions with dopamine receptors in the ventral striatum. Eur $J$ Pharmacol 251: 229-236.

Paxinos G, Watson C (1998). The Rat Brain in Stereotaxic Coordinates. Academic Press: New York.

Sams-Dodd F (1998). Effects of continuous D-amphetamine and phencyclidine administration on social behaviour, stereotyped behaviour, and locomotor activity in rats. Neuropsychopharmacology 19: 18-25.

Selemon LD, Goldman-Rakic PS (1999). The reduced neuropil hypothesis: a circuit based model of schizophrenia. Biol Psychiatry 45: 17-25.

Sesack SR, Pickel VM (1992). Prefrontal cortical efferents in the rat synapse on unlabeled neuronal targets of catecholamine terminals in the nucleus accumbens septi and on dopamine neurons in the ventral tegmental area. J Comp Neurol 320: 145160.

Steffensen SC, Svingos AL, Pickel VM, Henriksen SJ (1998). Electrophysiological characterization of GABAergic neurons in the ventral tegmental area. J Neurosci 18: 8003-8015.

Szeszko PR, Bilder RM, Dunlop JA, Walder DJ, Lieberman JA (1999). Longitudinal assessment of methylphenidate effects on oral word production and symptoms in first-episode schizophrenia at acute and stabilized phases. Biol Psychiatry 45: 680-686.
Taber MT, Baker GB, Fibiger HC (1996). Glutamate receptor agonists decrease extracellular dopamine in the rat nucleus accumbens in vivo. Synapse 24: 165-172.

Takahata R, Moghaddam B (1998). Glutamatergic regulation of basal and stimulus-activated dopamine release in the prefrontal cortex. J Neurochem 71: 1443-1449.

Takahata R, Moghaddam B (2000). Target-specific glutamatergic regulation of dopamine neurons in the ventral tegmental area. $J$ Neurochem 75: 1775-1778.

Thompson TL, Moss RL (1995). In vivo stimulated dopamine release in the nucleus accumbens: modulation by the prefrontal cortex. Brain Res 686: 93-98.

Umbricht D, Schmid L, Koller R, Vollenweider FX, Hell D, Javitt DC (2000). Ketamine-induced deficits in auditory and visual context-dependent processing in healthy volunteers: implications for models of cognitive deficits in schizophrenia. Arch Gen Psychiatry 57: 1139-1147.

Walberg CB, McCarron MM, Schulze BN (1983). Quantitation of phencyclidine in serum by enzyme immunoassay: results in 405 patients. J Anal Toxicol 7: 106-110.

Wang C, Showalter VM, Hillman GR, Johnson KM (1999). Chronic phencyclidine increases NMDA receptor NR1 subunit mRNA in rat forebrain. J Neurosci Res 55: 762-769.

Weinberger DR, Lipska BK (1995). Cortical maldevelopment, antipsychotic drugs, and schizophrenia: a search for common ground. Schizophr Res 16: 87-110.

Weir E (2000). Raves: a review of the culture, the drugs and the prevention of harm [see comments]. Cmaj 162: 18431848.

Wolf ME, Xue CJ, White FJ, Dahlin SL (1994). MK-801 does not prevent acute stimulatory effects of amphetamine or cocaine on locomotor activity or extracellular dopamine levels in rat nucleus accumbens. Brain Res 666: 223-231.

Yonezawa Y, Kuroki T, Kawahara T, Tashiro N, Uchimura H (1998). Involvement of gamma-aminobutyric acid neurotransmission in phencyclidine-induced dopamine release in the medial prefrontal cortex. Eur J Pharmacol 341: 45-56. 